\title{
Percutaneous Microcompression for Idiopathic Trigeminal Neuralgia: curative effects and complications
}

yi ma ( $\square$ doctormayi@126.com )

Liaoning Cancer Institute and Hospital https://orcid.org/0000-0001-5147-5418

Yan-feng Li

Shengjing Hospital of China Medical University

Hai-tao Huang

Shengjing Hospital of China Medical University

Bin Wang

Shengjing Hospital of China Medical University

Quan-cai Wang

Shengjing Hospital of China Medical University

Research article

Keywords: trigeminal neuralgia, percutaneous balloon compression, side effects, complications

Posted Date: March 28th, 2020

DOl: https://doi.org/10.21203/rs.3.rs-19565/v1

License: (c) (i) This work is licensed under a Creative Commons Attribution 4.0 International License. Read Full License 


\section{Abstract}

Background. We aimed to present the immediate and long term effect of percutaneous balloon compression (PBC) for idiopathic trigeminal neuralgia (ITN).

Methods. ITN patients who underwent PBC for the first time in the past seven years were enrolled. Base line data and immediate postoperative outcomes were collected by reviewing the medical records and long term results. Kaplan-Meier curve, life-table analysis proportional-hazards analysis were utilized to assess the long term results and the likelihood of tic recurrence.

Results. 12,797 patients were enrolled. Immediate after the PBC procedure, complete and partial pain relief were achieved in $95.6 \%$ and $1.1 \%$ patients respectively, with no relief in $1.7 \%$ patients; the common side effects on the affected side of face included the sense loss in $98.9 \%$ patients, with $3.8 \%$ of them experienced sense loss combined abnormal sense; masseter weakness in $90.6 \%$, herpes eruption in $51.4 \%$, corneal reflex weakness or loss in $12.7 \%$ patients. The fewer perioperative complications covered diplopia in 139 patients (1.1\%), partial hearing loss in 190 patients $(1.5 \%)$, vascular complications in 5 patients $(0.05 \%)$, brainstem hematoma in one patient $(0.01 \%)$, ischemic stroke in two patients $(0.02 \%)$, intracranial hemorrhage in 11 patents $(0.09 \%)$, and intracranial infection in one patient $(0.01 \%)$ patients. Of three deaths happened in the perioperative period, two died of intracranial hemorrhage, and the other one died of intracranial infection. 5794 (49.2\%) patients, who were followed than one year after the procedure, were included in the follow-up study, with the median follow-up period of 7.2 years. Complete and partial pain relief were obtained in $82.9 \%$ and $6.8 \%$ patients respectively, while the pain recurrence occurred in $8.5 \%$ patients. Side effects included sense loss without abnormal sense in $54.3 \%$, with acceptable abnormal sense in $6.0 \%$, and with severe abnormal sense in $2.0 \%$ patients. Masseter weakness was reported by $7.5 \%$ patients. $96.4 \%$ patients were satisfied with the procedure.

Conclusion. Our study shows PBC is a safe, simple and effective procedure, with both immediate and long-term success rates, acceptable side effects and fewer deadly complications, should be considered as one of the best choice for the treatment of ITN patients.

\section{Introduction}

Trigeminal neuralgia (TN), or tic douloureux, is a painful, debilitating condition characterized by sudden, usually unilateral, severe brief stabbing recurrent pains in the distribution of one or more branches of the 5th cranial nerve[1], Pharmacotherapy is generally the mainstay of treatment of TN, however, loss of pharmacological effect or intolerability of the medications is experienced in almost half of patients by 10 years' treatment[2]. Fortunately, surgical options are available once medical treatment fails.

PBC was first introduced by Mullan and lector in 1983[3]. Traditionally, PBC was reserved for older patients or patients who might not be able to endure a craniotomy for MVD. Anyway, the modality has been accepted by more and more surgeons owing to its excellent outcomes obtained from many publications[4-12]. However, definitive evaluation of PBC may not be extracted from the publications 
because of different description, the inhomogeneous population, short duration of follow up, and most importantly, the limited number of patients included in most of the series.

We initiated to treat TN by PBC from December 2000 after the senior author Dr. Yi Ma came back from institute of neurosurgery, catholic university medical school (Rome) and learnt the technique from Dr. Mario Meglio. Up to present time, more than 16, 000 PBC procedures have been performed for TN patients in our department. To our knowledge, it will be the largest series of PBC reported up to date. With this article, our purpose is to present our experience gained from the large series and verify the effect of $\mathrm{PBC}$ for idiopathic trigeminal neuralgia.

\section{Methods}

\section{Patient Population}

Ethics approval for this study was obtained from the institutional ethics committee of Liaoning Provincial People's Hospital. Between 2000 and 2017, after giving written informed consent, patients meet the following criterion were enrolled in this study: 1) idiopathic TN patients, characterized by recurrent unilateral brief, electric, shock-like pains, abrupt in onset and termination, limited to the one or more divisions of the trigeminal nerve, imaging examination excluded other diagnosed disorder ; 2) underwent PBC for the first time. Therefore, the secondary TN patients, the patients with the syndrome other than idiopathic TN syndromes, and the patients who had received PBC procedures previously were excluded from the study. After these exclusions, 12,797 consecutive ITN patients with medically refractory trigeminal pain and/or failed previous surgical procedure remained in the study group (those bilateral ITN patients who underwent twice procedures on both side of face were accounted for two times). For definition of the syndrome of TN, we adopted the classification as proposed by the International Association for the Study of Pain in 1994.

A careful baseline examination was undergone and particular attention to cardiovascular status was stressed. Preoperative magnetic resonance imaging and/or computed tomography studies were obtained for the distinction of secondary TN from ITN patients. Drugs that influence hemostasis was tapered off preoperatively and resumed on first postoperative day.

\section{Operative Technique}

PBC was performed in operating room with the aid of C-arm fluoroscopic imaging under general anesthesia using endotracheal intubation, which was exchanged by laryngeal mask in later years. We used procedure described by Mullan and Lichtor[3]in 1983 with minor modifications. A transcutaneous cardioversion device is close by and ready to be used once a severe cardiac depression response should occur. 
Patients were placed in natural supine position. The entry point was $2-3 \mathrm{~cm}$ lateral to the angle of the mouth. A 14-gauge special designed needle was passed percutaneously medial to the coronoid process and aimed toward the foramen ovale using Härtel guidelines under the guidance of lateral fluoroscopic imaging, and the final needle position was adjusted to be at or within $5 \mathrm{~mm}$ entrance of the foramen ovale. No. 4 French Fogarty balloon catheter was used till 2016, from then on, a new type of catheter (Matreneu, Percutaneous balloon compression kits, Shenzhen Shineyard Medical Device Co., Lid), specially designed for the PBC procedure, was used in the latter part of the series. The catheter was inserted through the cannula until about $12-16 \mathrm{~mm}$ of the catheter lay beyond the cannula tip, and at the ideal state, the end point of the catheter should locate at 2-3 $\mathrm{mm}$ exceeding the clival line with catheter showing a curve as first quarter moon on the lateral fluoroscopic imaging. In our practice, pear shape, pear-like shape and dumbbell shape were all considered to be satisfied shape [Fig, 1-3], in indicating a correct balloon positionand precondition for satisfied curative effects. The balloon catheter was inflated by slowly injecting radio-opaque contrast (Omnipaque) using a $1 \mathrm{ml}$ syringe until a satisfied balloon shape was obtained. The usual dosage of contrast material was 0.5 to $0.7 \mathrm{ml}$, but it can be varied from 0.3 to $1.0 \mathrm{ml}$, but it can be varied from 0.3 to $1.0 \mathrm{ml}$ according to the discrepancy of the volume of Mechel's cave between individual cases. In the beginning stage of our practice, the duration of balloon compression was about 6 minutes, but it was decreased to about 2 minutes in the later part of the series. After compression, the balloon was deflated and withdrawn together with the needle. Firm pressure was applied to the puncture site for minutes to prevent hematoma. The patient was usually discharged two days after the procedure.

Sometimes, the needle would be repositioned to foramen ovale along a new trajectory and angle for a satisfied shape was obtained. Anyway, in case foramen ovale was not to be crossed after making great efforts, the patient would be advised to accept vascular decompression surgery if his/her general physical condition was permitted.

Occasionally, a special shape Meckle's cave was met, which resulted in the easily floating of balloon forward into posterior fossa or backward into the larger Meckle's cave through the porus trigeminal. To deal with this situation, at first, small volume balloon bubble, by injecting radio-opaque contrast about $0.3 \mathrm{ml}$, was formed outside the porus trigeminal by inserting the deflated catheter 2-3 mm deeper along the previous pathway; then the radio-opaque contrast was slowly withdrawn from the bubble step by step while maintaining certain force withdrawing the balloon backward into Meckle's cave until a dumbbell shape was obtained. Balloon rupture was an annoying condition happened during inflating the balloon in small number patients. For these cases, the procedures were accomplished by beginning the compression with lower balloon dosage, increasing the dosage step by step, and expanding the duration of compression time to 3 to 5 minutes [Fig. 4].

Trigeminal cardiodepressive response was frequently happened when introducing needle nearby or into the oval foramen and in the beginning stage of inflating balloon in Mechel's cave, represented with marked bradycardia, not unusual, cardiac arrest. The response was usually short lasting, resolved spontaneously within a few seconds. A bulus of atropine was needed in a number of cases before 
continuing the procedure. Here, what need to be addressed was the remarkable hypertensive response readily subsequent the trigeminal cardiodepressive, which must be carefully controlled by anesthesia.

\section{Data Collection And Outcome Criteria}

The medical and surgical records were retrospectively reviewed and analyzed for the collection of database of the preoperative general characteristics of the patients, the surgical manipulation, and perioperative outcomes (at discharge). Visual analog scale has been used for pain assessment in our series. Complete relief of pain was defined as the absolutely absence of pain without medication for original trigeminal; partial relief was defined as at least 80 percent reduction in pain as assessed by the patient, while less doses of medication was allowed in this category; otherwise, the present procedure would be classified as failure. During the follow-up period, any level pain occurred for a complete relief patient, or the original pain became worse for a partial relief patient were considered as recurrence.

Sense loss was divided into four ranks: no sensory loss; hypothesia, sensory loss without unpleasant sensations; dysesthesia, unpleasant sensations in the area of sensory loss; anesthesia dolirosa, marked dysesthesias, the patient described it as very discontented, requiring medical treatment.

The satisfactory evaluation questionnaire we used in follow-up study included three items: 1) whether or not you satisfy with the present outcomes? 2) Would you like to accept the PBC again once your trigeminal neuralgia syndrome recurred? 3) Would you like to recommend the PBC treatment to your friends or others who suffered from the trigeminal neuralgia syndrome? The patients who agreed with two of the three items was defined as satisfied with the procedure, while whose agreed with all three items was defined as very satisfied with the procedure.

\section{Statistical Analysis}

Kaplan-Meier curve and life-table analysis were used to calculate rates of effective and recurrence respectively. Proportional-hazards analysis was used to relate the likelihood of recurrence of tic syndrome with variables.

\section{Results}

A total 12,979 consequent idiopathic trigeminal neuralgia patients underwent PBC at the neurosurgery department, People's Hospital in Shenyang between December 2000 and December 2017, were enrolled in this study, and the base-line data of these patients are summarized in Table 1, including 242 patients suffered from bilateral tic. Of 41 patients, among these 242 patients with bilateral symptoms, underwent twice PBC procedures for controlling the pain on the both sides of the face, were counted twice time in the following study. All together, 12,838 PBC procedures were performed in these 12,797 patients. 
Table 1

Base-Line Characteristics of the 12,797 Study Patients

Characteristic

Sex

Male

Female

Unclear*

Age at surgery $(-\mathrm{yr})$

Range

Median

Age at onset of symptoms

Range

Median

Preoperative duration of symptoms - yr

Range

Median

Prior carbamazepine treatment

Number of user

Rate of effective

Site of symptoms

Left side

Right side

Bilateral\&

Unclear*

Prior surgical treatment
Value (\%)

$5442(42.5)$

7316 (57.2)

$39(0.3)$

17-98

61.3

7-92

53.3

$<1-70$

7.4

$11,106(86.8)$

$4,520(35.3)$

$7,802(61.0)$

242 (1.9)

233 (1.8)

*there were missing figure in some records.

\&among the 242 bilateral trigeminal neuralgia patients, 41 cases underwent bilateral PBC procedures, and those 41 cases are counted twice in the following study.

$\S \mathrm{V} 1, \mathrm{~V} 2$ and V3 denote the ophthalmic, maxillary and mandibular divisions of the trigeminal nerve respectively 


\begin{tabular}{|ll|}
\hline Characteristic & Value (\%) \\
\hline MVD & $353(2.8)$ \\
\hline Peripheral -nerve procedures & $172(1.3)$ \\
\hline Radiofrequency ganglion lesions & $749(5.9)$ \\
\hline Radiosurgery treatment & $749(5.9)$ \\
\hline Distribution of the pain§ & $270(2.1)$ \\
\hline V1 & $2,514(19.6)$ \\
\hline V2 & $2,382(18.6)$ \\
\hline V3 & $1,420(11.1)$ \\
\hline V1 and V2 & $4,179(32.7)$ \\
\hline V2 and V3 & $1562(12.2)$ \\
\hline V1 and V2 and V3 & \\
\hline *there were missing figure in some records. & \\
\hline \&among the 242 bilateral trigeminal neuralgia patients, 41 cases underwent bilateral PBC procedures, \\
\hline and those 41 cases are counted twice in the following study. \\
\hline $\begin{array}{l}\text { SV1, V2 and V3 denote the ophthalmic, maxillary and mandibular divisions of the trigeminal nerve } \\
\text { respectively }\end{array}$ \\
\hline
\end{tabular}

The perioperative outcomes of these 12,838 cases are outlined in Table 2 and summarized as follows: complete pain relief in 95.6, partial relief in 1.1, and no relief in 1.7 percent patients; no sensory loss in 4.9, Hypothesia in 91.3, and dysesthesia in 3.8 percent patients; masseter weakness in 90.6 percent patients, usually resolved within 3-5 months; corneal reflex weakness or loss in 12.7 percent patients; diplopia in 1.1 percent patients, usually recovered within 3 months; herpes eruption in 51.4 percent patients, the rate of this syndrome diminished significantly after the perioperative usage of an-viral medications in the latter part of the series; partial hearing loss in 1.5 percent patients. Penetrating the foreman ovale and obtaining the satisfied balloon shape should be the major technique notes of PBC procedure. We met difficulties for penetrating foreman ovale in 4.6 percent cases. In our series, we failed to obtain satisfied balloon shape in $0.6 \%$ cases, even though, in a certain stances, hours had exhausted by adjusting the trajectory repeatedly. 
Table 2

Perioperative Outcomes of 12838 patients

\begin{tabular}{|ll|}
\hline Feature & Value (\%) \\
\hline Immediate pain relief & \\
\hline Complete relief & $12,273(95.6)$ \\
\hline Partial relief & $141(1.1)$ \\
\hline No relief & $221(1.7)$ \\
\hline Unclear* & $203(1.6)$ \\
\hline Sensory loss & \\
\hline No sensory loss & $629(4.9)$ \\
\hline Hypothesia & $11,721(91.3)$ \\
\hline Dysesthesia & $488(3.8)$ \\
\hline Masseter weakness & $11,631(90.6)$ \\
\hline Corneal reflex weakness or loss & $1,630(12.7)$ \\
\hline Diplopia & $139(1.1)$ \\
\hline Herpes eruption & $6,608(51.4)$ \\
\hline Partial hearing loss & $190(1.5)$ \\
\hline Difficulties for penetrating & $591(4.6)$ \\
\hline Unsatisfied balloon shape & $78(0.6)$ \\
\hline Rupture of balloon during procedure & $963(7.5)$ \\
\hline Artery bleeding & $6(0.05)$ \\
\hline Intracranial hemorrhage & $11(0.09)$ \\
\hline Vascular complications & $5(0.05)$ \\
\hline Brainstem hematoma & $1(0.01)$ \\
\hline Ischemic stroke & $2(0.02)$ \\
\hline Intracranial infection & $10.01)$ \\
\hline$*$ there were missing figure in some records. \\
\hline
\end{tabular}

Arterial bleeding happened in $6(0.05 \%)$ cases during penetrating the foramen ovale,the procedures were repeated steadily by adjusting the trajectory and repositioning the needle after compressing cheek 
hematoma for minutes. Fortunately, satisfied balloon shape was obtained in all these six cases.

Brainstem hematoma occurred in one case $(0.01 \%)$ in the earlier stage of our series because of inserting the catheter unintentionally too deep, into the brainstem, which resulted in permanent partial paralysis in contralateral leg.

Intracranial hemorrhagiccomplications happened in $11(0.09 \%)$ patients in the series, which resulted in the death of two patients. Of these two death cases, one died of the multiple hematomas in different intracranial sites, which was considered due to the evident fluctuate of blood pressure during the manipulation; the other one died of bilateral huge subdural hemorrhage, which was believed soured from injury of cavernous sinus by misleading catheter. Ventriculoperitoneal shunt surgeries were needed in four patients who suffered from the hydrocephalus subsequent to the subarachnoid hemorrhage, while the other 5 patients recovered spontaneously without surgical interventions.

Vascular complications occurred in five cases( $0.05 \%)$, which consisted of internal carotid fistula (CCF) in three cases and external carotid artery system fistula in two cases. All these patients presented relative syndromes immediately after the procedure. Endovascular coils and balloon occlusion techniques were used to treat these five cases successfully after conventional methods had failed to heal their syndromes. Ischemic stroke occurred in 2 cases $(0.02 \%)$, and the causes were unclear.

The only intracranial infection happened in a 37 years old woman, who presented typical right side trigeminal neuralgia syndrome combined ipsilateral active otitis media before the PBC procedure. After the procedure, her presented severe headache and fever. Magnetic resonance image performed on the 10th postoperative day showed a low density area localized in the ipsilateral cerebellum toward Mechel' cave, which was suspected to be an abscess. Unfortunately, the patients died on the 18th postoperative day although ample antimicrobial therapy was used.

After excluding those 507 cases with less than a year of follow-up time and 152 patients who died of reasons other than the PBC operations, a total 5794 patients were included in the follow-up study. The follow-up rate at 17 years was $49.2 \%$, with the median follow-up period of 7.2 years. The follow-up results are shown in Table 3. Complete pain relief was obtained in 82.9, partial relief in, and no relief 1.8 percent cases; while pain recurrence occurred in 8.5 percent cases; Hypothesia in 54.3, dysesthesia in 6.0, and Anesthesia dolorosa in 2.0 percent cases; some level of masseter weakness remained in $7.5 \%$ cases; the procedures are considered to be very satisfied in $35.4 \%$ cases, satisfied in $61 \%$ cases, and unsatisfied in $3.6 \%$ cases. 
Table 3

The follow-up results of 5,794 patients

with more than one year follow-up

\begin{tabular}{|ll|}
\hline Feature & Value (\%) \\
\hline Pain relief & \\
\hline Complete relief & $4803(82.9)$ \\
\hline Partial relief & $393(6.8)$ \\
\hline No relief & $105(1.8)$ \\
\hline Pain recurrence & $493(8.5)$ \\
\hline Hypothesia & $3147(54.3)$ \\
\hline Dysesthesia & $348(6.0)$ \\
\hline Anesthesia dolorosa & $116(2.0)$ \\
\hline Masseter weakness & $437(7.5)$ \\
\hline Satisfactory evaluation & \\
\hline Very satisfied & $2050(35.4)$ \\
\hline Satisfied & $3533(61.0)$ \\
\hline Unsatisfied & $211(3.6)$ \\
\hline
\end{tabular}

The Kaplan-Meier curves show more than $86 \%$ success rate (including both complete pain relief and partial relief) 5 years after the procedure, more than $83 \%$ success rate 10 years after the procedure, and the success rate will be stable at 77 percent 15 years after the procedure Fig. 5. The life-table Fig. 6 verified that annual risk of recurrence was less than 7 percent 5 years after the procedure, less than 4 percent after 10 years, and remained stable at 2 percent from the 15th year after the procedure.

Proportional-hazards analysis was used to relate the likelihood of the postoperative recurrence of tic to the following variables: male or female; age less or more than 70 years at onset; symptoms lasting less or more than 10 years before the procedure; and side of the face where tic occurred. The results were summarized in Table 4, and none of the factors studied showed significant association with recurrence.

\section{Discussion}

The first attractive feature of PBC is the excellent immediate success rate, which was identically reported by nearly every published paper[3-6, 9-11, 13], anyway, there is some level difference about the recurrence rate between studies. Skirving reported that all but one of their 522 successful procedures to 496 patients experienced immediate pain relief. The recurrence rate was $19.2 \%$ within 5 years and $31.9 \%$ 
over the entire study period, with a mean follow up duration of 10.7 years[11]. In another larger series of PBC reviewed, Benaissa reported "appreciable pain relief" in $92.7 \%$ patients one month after the procedure in their 901 patients; while pain free remained in $62 \%$, and recurrence occurred in $27.8 \%$ of their patients with mean follow-up of 16.5 years[13]. Anyway, in a study by Jason[14] (A review of percutanous...), the authors concluded recurrence rate as high as $26 \%$ with a mean time of 18 months.

Our results seemed supper to those reported by others, with complete pain relief in 95.6 and partial pain relief in 1.1 percet patients immediately after the procedure; with median follow-up time of 7.2 years, complete pain relief remained in 82.9, partial pain relief in 6.8 percent patients; the pain recurrence happened in 8.5 percet patients. We believed our supper' results may be ascribed to following reasons. Firstly, in comparison with our universal idiopathic trigeminal neuralgia patients, many studies were composed by cohort of patients with discrepancy, such as patients with non idiopathic trigeminal neuralgia symtoms, multiple sclerosis were also included, which was supposed to affect the outcomes negatively. As a example, in a series report by Tommy[15], the author found the median pain-free time without medication of 28 months in their 100 consecutive PBC procedure. While those 100 patients were subdivided into primary TN $(n=77)$ and TN secondary to multiple sclerosis $(n=23)$, the median pain-free times were 33 months and 24 months $(P=0.2)$ respectively. Secondly, we thought it is reasonable that the operator's experience achieved from larger series have positive influence on the results. At last, it is worth noting that the satisfied balloon shape, which have been considered as golden standard for success, were achieve in $99.7 \%$ patients in our series.

In fact, we believe that the success rate might be increased in further if the patients with "delayed heal" had also been included. Here, the "delayed heal" denoted that the pain did not cease immediately after the surgery, instead, it might fade away within weeks or months. In practice, this phenomenon occurred not uncommon in our series. Our strategy toward this kind of patients was to suspend the repeated surgical procedures till at least three months in case the satisfied balloon shape and some level sense loss on the affected face, as expected, were obtained in the original procedure.

As an ablative procedure at peripheral level of trigeminal nerve, some level sense loss is understandable and is expected, which was also commonly considered as an inevitable side effects in a successful case. Our results, 95.1 percent patients experienced hypothesia immediately after the procedure, is in agreement with others. However, it worth noted, there were still $62.3 \%$ (including hypothesia in $54.3 \%$, dysesthesia in $6 \%$ and anesthesia dolorora in $2 \%$ ) patients experienced sensoryloss in different level with median follow-up 7.2 years, which is obviously differ from many of the studies, they usually believed that it will recover within $3-9$ months $[9,11,16]$, and we are not able to give a reasonable explanation for this situation. As a major shortcoming of the PBC procedure, troublesome dysesthesia are often addressed and the rate of $2.8 \%-11.4 \%$ was also reported in literature $[5,6,10,17,18]$. Our results, with dysesthesia in $6 \%$ and anesthesia dolorosa in $2 \%$ patients were roughly in line with results reported by others.Masseter muscle weakness is another common side effect, which has been mentioned in many reports[11, 13,15 , 19]. In a special designed study[20], the author concluded that the masster muscle weakness should be expected in all cases after PBC procedure, and it would usually resolve within 12 months. In our series, 
90.6 percent patients experienced masster muscle weakness immediately after the procedure, while the symptom remained in 7.5 percent patients in the follow-up study.

Compared with those common side effects abovementioned, diplopia is one of the fewer complications, happened in 1.1 percent patients immediately after the procedure and usually resolved spontaneously within 3 months in our series. In a specially designed paper for studying the diplopia, the author noted six patients with diplopia postoperatively, and they found that the balloon was inflated outside Meckel's cave in four, the balloon was initially inflated too deeply in one patient, and probably aberrance anatomy of Meckel's cave in one patient[21].

Although numerous reports have established the safety of PBC in the treatment of trigeminal neuralgia, the deadly complications have been reported in some series[6, 10, 12, 22-25]. Brown and Pilitsis reported one of their patients died of diffuse subarachnoid hemorrhage from dural arteriovenous fistula in their 65 procedures performed in 56 consecutive patients over 4 years.[26]. The other death was reported as the result of unsuccessful attempts to penetrate the foramen ovale, which led to a brainstem hematoma and subsequent death[5]. Our result, on the whole, are broadly in line with those of the literature with three deaths occurred in our series. Two of them died of intracranial hemorrhage, and the other one died of intracranial infection.

In reviewing the literature, vascular injury complications due to $\mathrm{PBC}$, such as duralarteriovenous fistula[27], dural arteriovenous malformations (DAVM)[10] and CCF[24]are rare. Unfortunately, we encountered 5 cases with vascular injury complications in our series $(0.05 \%)$, and we are not able to give an exact explanation to any individual case. It is postulated that the rationale behind this rare complication may be twofold: an anatomical variation on one side and inappropriate penetration of needle or catheter on the other side.

\section{Conclusions}

Our large series verified that percutaneous balloon compression is an effective procedure for the treatment of idiopathic trigeminal neuralgia patients, with both higher immediate and long-term success rates, acceptable side effects and fewer deadly complications.

\section{Abbreviation}

ITN = idiopathic trigeminal neuralgia; $\mathrm{PBC}=$ percutaneous balloon compression; $\mathrm{TN}$ = trigeminal neuralgia; $\mathrm{CCF}=$ internal carotid fistula

\section{Declarations}

\section{Ethics approval and consent to participate}


Ethics approval for this study was obtained from the institutional ethics committee of Liaoning Provincial People's Hospital.

\section{Consent for publication}

All patients have consent for publication.

\section{Availability of data and material}

The datasets used or analysed during the current study are available from the corresponding author on reasonable request.

\section{Competing interests}

The authors report no conflict of interest concerning the materials or methods used in this study or the findings specified in this paper.

\section{Funding}

This study was supported by grants from the Liaoning Province Natural Science Foundation of China (No.20180530027 to Dr Huang).

\section{Authors' contributions}

Yi Ma: Identifying research topics; Revision of manuscript. Yan-feng Li: Data collection. Hai-tao Huang: Data collection; Revision of manuscript. Bin Wang: Data collection; Statistical analysis of data. Quan-cai Wang: Data collection; Revision of manuscript. All authors have read and approved the final manuscript, and ensure that this is the case.

\section{Acknowledgments}

We acknowledge the assistance of Servbus Technology (Beijing) Co. in the collection of follow-up data.

\section{References}

1. Classification of chronic pain. Descriptions of chronic pain syndromes and definitions of pain terms. Prepared by the International Association for the Study of Pain, Subcommittee on Taxonomy. Pain Supplement. 1986;3:S1-226.

2. Nurmikko TJ, Eldridge PR. Trigeminal neuralgia--pathophysiology, diagnosis and current treatment. British journal of anaesthesia. 2001;87 1:117-32.

3. Mullan S, Lichtor T. Percutaneous microcompression of the trigeminal ganglion for trigeminal neuralgia. Journal of neurosurgery. 1983;59 6:1007-12; doi: 10.3171/jns.1983.59.6.1007.

4. Abdennebi B, Bouatta F, Chitti M, Bougatene B. Percutaneous balloon compression of the Gasserian ganglion in trigeminal neuralgia. Long-term results in 150 cases. Acta neurochirurgica. 1995;136 1- 
2:72-4.

5. Abdennebi B, Mahfouf L, Nedjahi T. Long-term results of percutaneous compression of the gasserian ganglion in trigeminal neuralgia (series of 200 patients). Stereotactic and functional neurosurgery. 1997;68 1-4 Pt 1:190-5; doi: 10.1159/000099922.

6. Baabor MG, Perez-Limonte L. Percutaneous balloon compression of the gasserian ganglion for the treatment of trigeminal neuralgia: personal experience of 206 patients. Acta neurochirurgica Supplement. 2011;108:251-4; doi: 10.1007/978-3-211-99370-5_39.

7. Belber CJ, Rak RA. Balloon compression rhizolysis in the surgical management of trigeminal neuralgia. Neurosurgery. 1987;20 6:908-13.

8. Correa CF, Teixeira MJ. Balloon compression of the Gasserian ganglion for the treatment of trigeminal neuralgia. Stereotactic and functional neurosurgery. 1998;71 2:83-9; doi: 10.1159/000029651.

9. Lichtor T, Mullan JF. A 10-year follow-up review of percutaneous microcompression of the trigeminal ganglion. Journal of neurosurgery. 1990;72 1:49-54; doi: 10.3171/jns.1990.72.1.0049.

10. Lobato RD, Rivas JJ, Sarabia R, Lamas E. Percutaneous microcompression of the gasserian ganglion for trigeminal neuralgia. Journal of neurosurgery. 1990;72 4:546-53; doi: 10.3171/jns.1990.72.4.0546.

11. Skirving DJ, Dan NG. A 20-year review of percutaneous balloon compression of the trigeminal ganglion. Journal of neurosurgery. 2001;94 6:913-7; doi: 10.3171/jns.2001.94.6.0913.

12. Spaziante R, Cappabianca P, Peca C, de Divitiis E. Subarachnoid hemorrhage and "normal pressure hydrocephalus": fatal complication of percutaneous microcompression of the gasserian ganglion. Case report. Neurosurgery. 1988;22 1 Pt 1:148-51.

13. Abdennebi B, Guenane L. Technical considerations and outcome assessment in retrogasserian balloon compression for treatment of trigeminal neuralgia. Series of 901 patients. Surgical neurology international. 2014;5:118; doi: 10.4103/2152-7806.137838.

14. Cheng JS, Lim DA, Chang EF, Barbaro NM. A review of percutaneous treatments for trigeminal neuralgia. Neurosurgery. 2014;10 Suppl 1:25-33; discussion doi: 10.1227/NEU.00000000000001687.

15. Bergenheim AT, Asplund $P$, Linderoth B. Percutaneous retrogasserian balloon compression for trigeminal neuralgia: review of critical technical details and outcomes. World neurosurgery. 2013;79 2:359-68; doi: 10.1016/j.wneu.2012.03.014.

16. Asplund $\mathrm{P}$, Linderoth B, Bergenheim AT. The predictive power of balloon shape and change of sensory functions on outcome of percutaneous balloon compression for trigeminal neuralgia. Journal of neurosurgery. 2010;113 3:498-507; doi: 10.3171/2010.2.JNS091466.

17. Du R, Binder DK, Halbach V, Fischbein N, Barbaro NM. Trigeminal neuralgia in a patient with a dural arteriovenous fistula in Meckel's cave: case report. Neurosurgery. 2003;53 1:216-21; discussion 21.

18. Li FY, Ma Y, Zou JJ, Li YF, Wang B, Huang HT, et al. Endovascular Treatment of Rare Vascular Complications of Percutaneous Balloon Compression for Trigeminal Neuralgia. Turk Neurosurg. 2016;26 2:215-8; doi: 10.5137/1019-51491TN.8037-13.0. 
19. de Siqueira SR, da Nobrega JC, de Siqueira JT, Teixeira MJ. Frequency of postoperative complications after balloon compression for idiopathic trigeminal neuralgia: prospective study. Oral surgery, oral medicine, oral pathology, oral radiology, and endodontics. 2006;102 5:e39-45; doi: 10.1016/j.tripleo.2006.03.028.

20. Chroni E, Constantoyannis C, Prasoulis I, Kargiotis O, Kagadis GC, Georgiopoulos M, et al. Masseter muscle function after percutaneous balloon compression of trigeminal ganglion for the treatment of trigeminal neuralgia: a neurophysiological follow-up study. Clinical neurophysiology : official journal of the International Federation of Clinical Neurophysiology. 2011;122 2:410-3; doi: 10.1016/j.clinph.2010.07.002.

21. Bergenheim AT, Linderoth B. Diplopia after balloon compression of retrogasserian ganglion rootlets for trigeminal neuralgia: technical case report. Neurosurgery. 2008;62 2:E533-4; discussion E4; doi: 10.1227/01.neu.0000316025.58915.10.

22. Arrese I, Lobato RD, Alen JF, Lagares A, Miranda P. Acute subdural and intratemporal hematoma as a complication of percutaneous compression of the gasserian ganglion for trigeminal neuralgia. Neurocirugia. 2005;16 2:177-82.

23. Kuether TA, O'Neill OR, Nesbit GM, Barnwell SL. Direct carotid cavernous fistula after trigeminal balloon microcompression gangliolysis: case report. Neurosurgery. 1996;39 4:853-5; discussion 5-6.

24. Langford P, Holt ME, Danks RA. Cavernous sinus fistula following percutaneous balloon compression of the trigeminal ganglion. Case report. Journal of neurosurgery. 2005;103 1:176-8; doi: 10.3171/jns.2005.103.1.0176.

25. Niu T, Kalia JS, Zaidat OO. Rare vascular complication of percutaneous balloon compression of trigeminal neuralgia treated endovascularly. Journal of neurointerventional surgery. 2010;2 2:147-9; doi: 10.1136/jnis.2009.001164.

26. Brown JA, Pilitsis JG. Percutaneous balloon compression for the treatment of trigeminal neuralgia: results in 56 patients based on balloon compression pressure monitoring. Neurosurgical focus. 2005;18 5:E10.

27. Henry HS, William HS. Operative Neurosurgical Techniques: Indications, Methods, and Results. 3 edn: Philadelphia press; 2000.

\section{Figures}




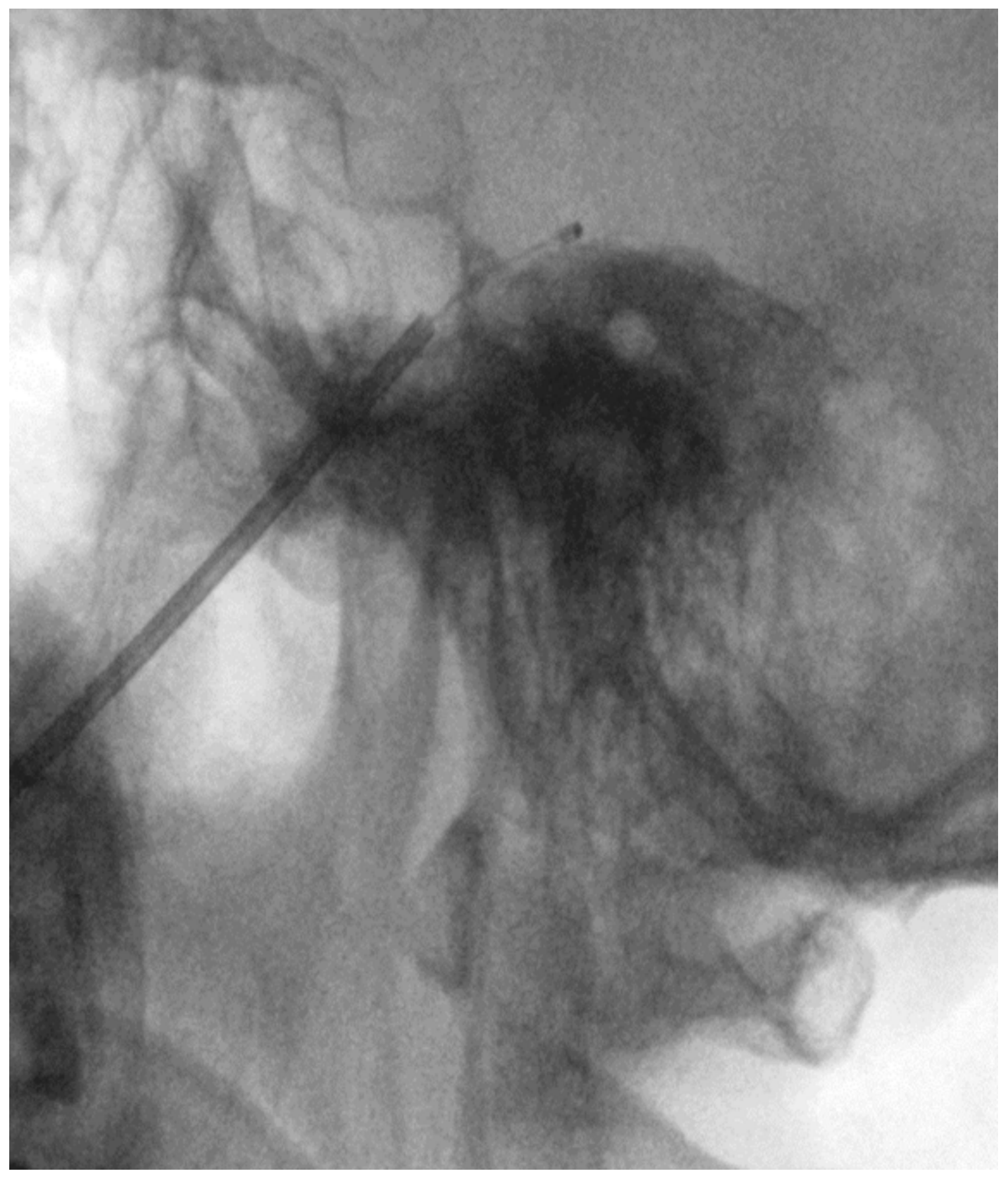

\section{Figure 1}

The end point of the catheter located at 2-3 mm exceeding the clival line showing a curve as fishing rod on the lateral fluoroscopic imaging 


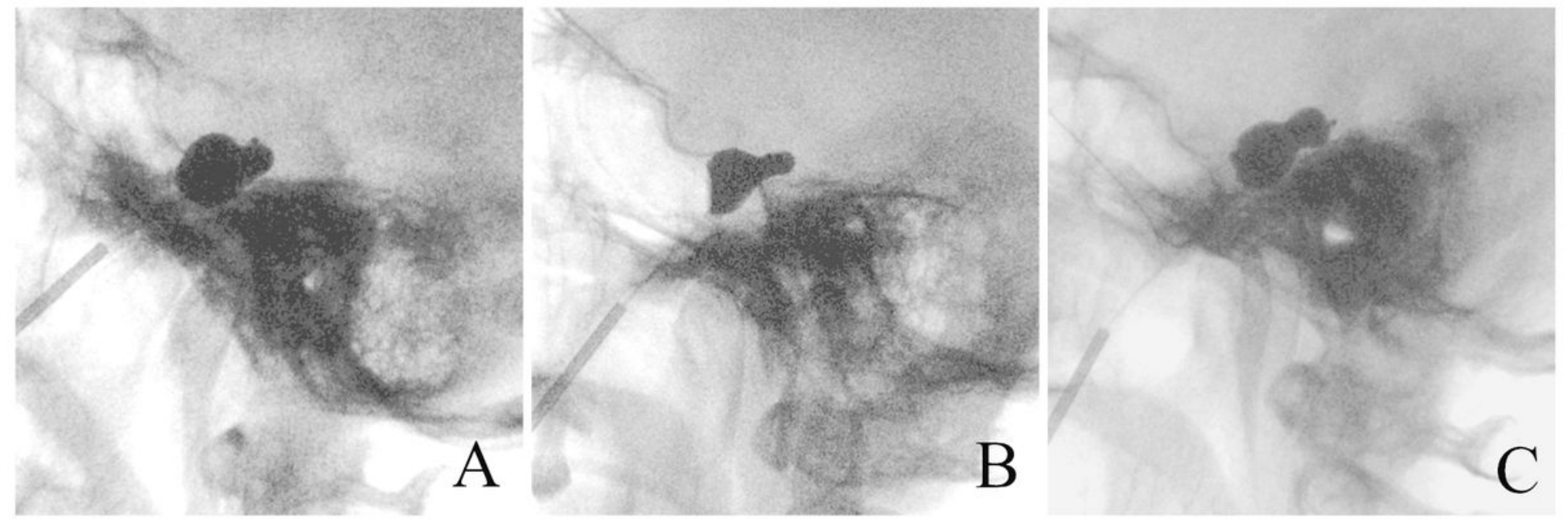

Figure 2

Intraoperative lateral radiographs demonstrating different balloon shape: pear shape (A), pear-like shape (B), and dumbbell shape (C).

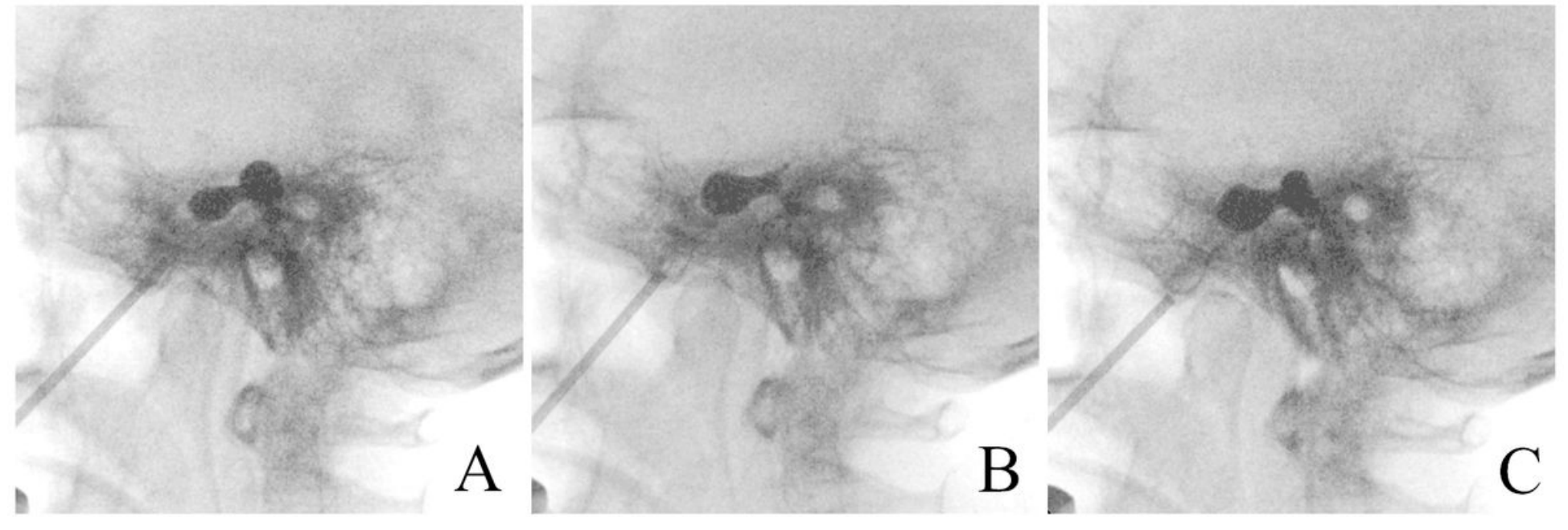

\section{Figure 3}

Intraoperative lateral radiographs demonstrating the transversion of balloon shape for a special shape Meckle's cave and porus trigeminal: small volume balloon bubble was formed outside the porus trigeminal (A), the balloon was withdrawn backward into Meckle's cave step by step (B), and a dumbbell shape was obtained at final(C) 

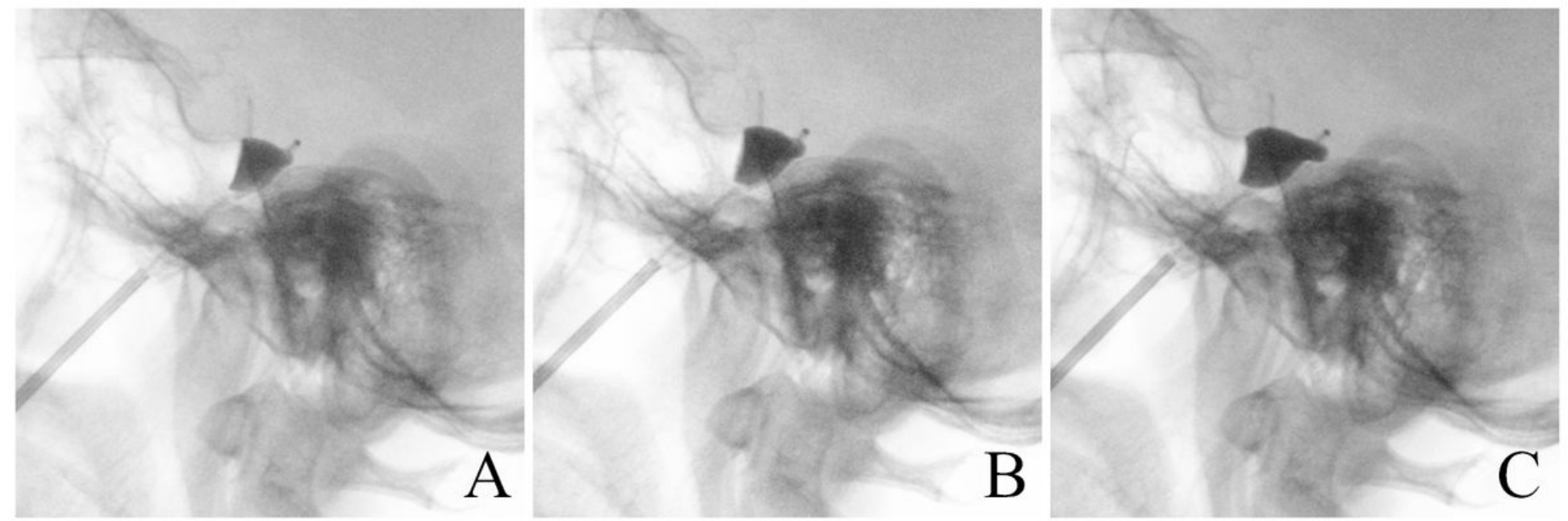

Figure 4

Intraoperative lateral radiographs showed the transversion of balloon shape for balloon rupture: the balloon was inflated with volume of $0.3 \mathrm{ml}(\mathrm{A}), 0.45 \mathrm{ml}(\mathrm{B})$, and $0.6 \mathrm{ml}(\mathrm{C})$. 
- Excellent outcome

- Good or excellent outcome

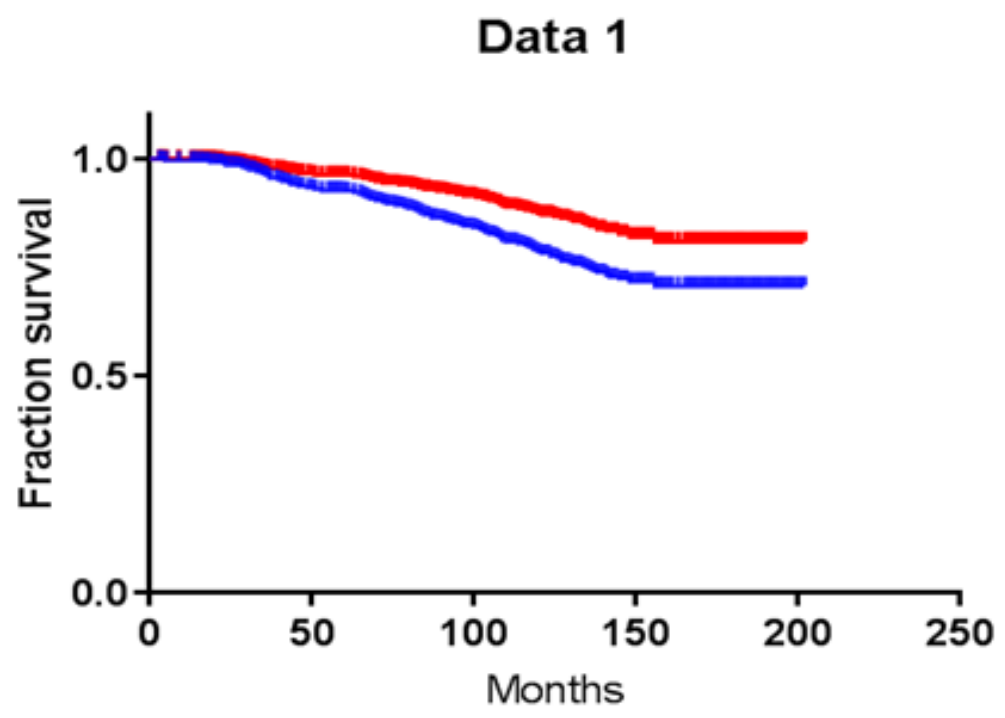

Months after First Operation

No. of Patients

Good or excellent $\quad 1700 \quad 1805 \quad 926 \quad 131$

$\begin{array}{lllll}\text { Excellent } & 1597 & 1670 & 865 & 122\end{array}$

Figure 5

Kaplan-Meier curves show the results of analysis of success rate (Y-axis) for patients with idiopathic trigeminal neuralgia treated by PBC during 7.2 years of follow-up (X-axis). 


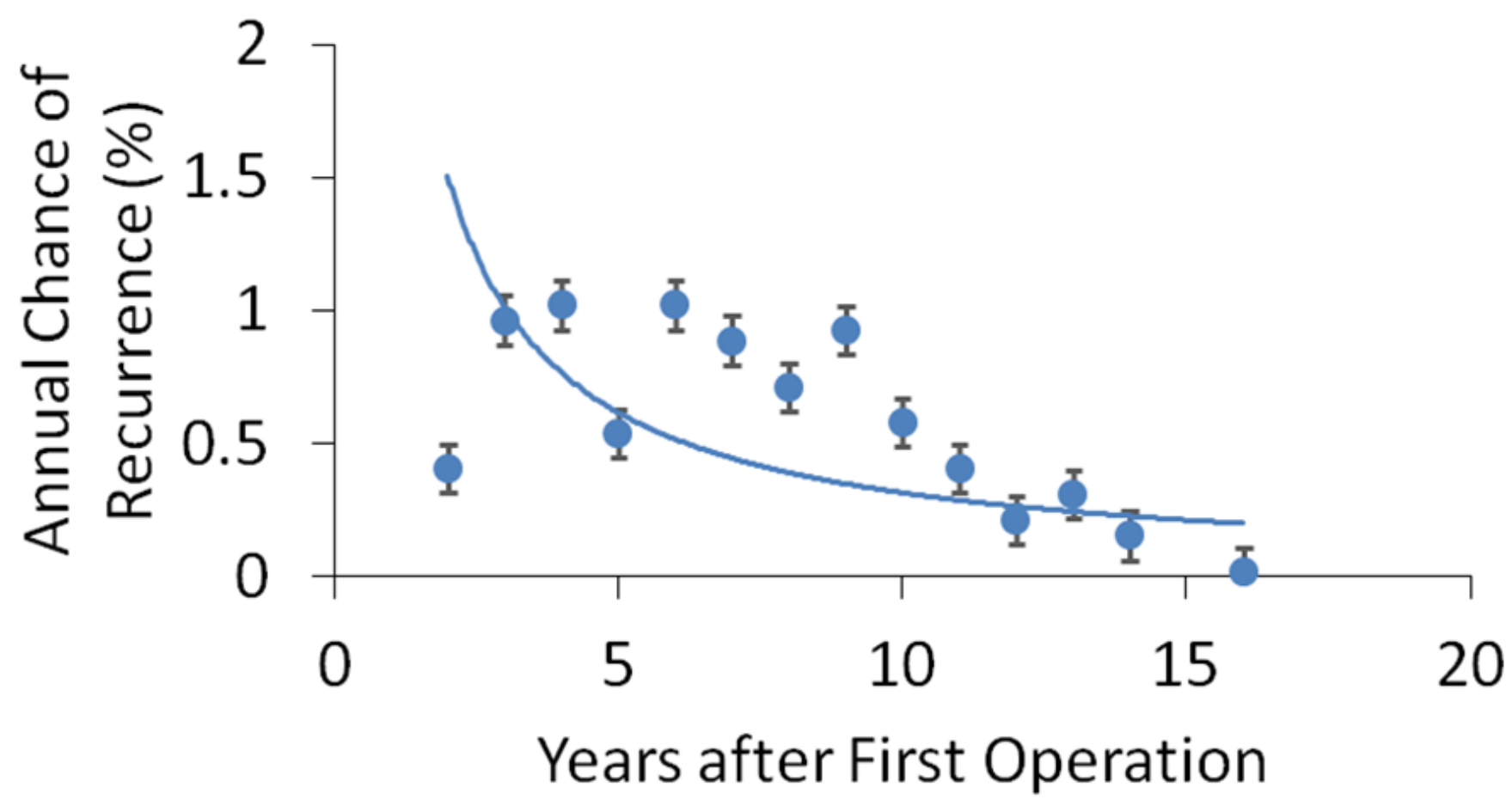

No. of Patients $1907 \quad 1856 \quad 463$

Figure 6

The life-table verify the annual risk of recurrence (Y-axis) for patients with idiopathic trigeminal neuralgia treated by PBC during 7.2 years of follow-up (X-axis).

\section{Supplementary Files}

This is a list of supplementary files associated with this preprint. Click to download.

- needlepic.jpg 